\title{
Bilateral Internal Mammary Lymph Nodes- Is Epsilateral Internal Mammary Node Treatment Sufficient?
}

\author{
Chaitali M. Waghmare \\ MGIMS \& KH, Sevagram, Maharashtra, India \\ Email: w.chaitali@gmail.com
}

Received 3 December 2015; accepted 21 December 2015; published 25 December 2015

Copyright (C) 2015 by author and Scientific Research Publishing Inc.

This work is licensed under the Creative Commons Attribution International License (CC BY).

http://creativecommons.org/licenses/by/4.0/

c) (i) Open Access

\begin{abstract}
Internal mammary nodes are addressed in high risk group of patients of carcinoma breast. Though there is crossover of lymphatics across the mid-line, only ipsilateral internal mammary nodes are evaluated or treated. Considering the negative impact on survival of patients with inner quadrant tumor, do we need to treat bilateral internal mammary nodes?
\end{abstract}

\section{Keywords}

Internal Mammary Nodes, Bilateral, Therapy, Breast Cancer

\section{Introduction}

Breast cancer is the second most common cancer in the world and ranks as the fifth cause of death from the cancer overall [1]. The tumor site is an important prognostic factor in breast cancer. Medial or inner quadrant tumors have negative impact on survival [2]. Internal mammary nodes (IMN) are commonly involved in inner quadrant tumors. They are addressed in high risk group patients of carcinoma breast like large size tumors, high axillary nodal burden and young age [3]. IMN evaluation improves nodal staging in breast cancer. Identification of high risk subgroup with IMN metastasis may benefit from altered adjuvant treatment regimen [4]-[6]. Both the surgery and radiotherapy (RT) for IMN management increase the cardiac and lung morbidity [6] [7]. Newer surgical techniques, conformal external beam RT techniques or intravascular RT decrease the cardiac and lung toxicity. But all the literatures present address only an epsilateral IMN.

\section{Discussion}

The incidence of IMN metastasis was around $10 \%$ in patients with negative axillary dissection and 20\% - 50\%

How to cite this paper: Waghmare, C.M. (2015) Bilateral Internal Mammary Lymph Nodes-Is Epsilateral Internal Mammary Node Treatment Sufficient? Journal of Cancer Therapy, 6, 1273-1275. http://dx.doi.org/10.4236/jct.2015.615139 
in patients with positive dissection [7]. The risk of IMN metastasis increases with increase in number of positive axillary nodes, tumor size and clinical stage. Central and medially located tumors have higher risk of IMN metastasis [8].

Both; the surgery and radiotherapy (RT) for IMN management increases the cardiac and lung morbidity [6] [9]. The lymph nodes located in upper three intercostal spaces are most likely to be involved/metastatic IMNs in patients with breast cancer which are located less deeply than the more inferior ones [7], hence can be addressed with relatively less morbid surgery or radiotherapy. Newer surgical techniques, conformal external beam RT techniques or intravascular RT decreases the cardiac and lung toxicity.

Generally only an epsilateral IMN are addressed during surgery or RT. One lymph node station higher than the involved node is usually included in radiation portals e.g. head and neck cancer, carcinoma cervix. In breast cancer considering an adequacy of axillary dissection and post operative histopathology report supraclavicular nodes are irradiated. IMN are irradiated if clinically/pathologically/radiologically positive nodes or inner quadrant tumors are present [10]. Veronesi et al. found an excellent survival after five years in 95\% patients with positive IMN after sentinel node dissection in internal mammary chain, treatment with RT to IMN and an appropriate systemic therapy [11]. Arriagada et al. suggested a beneficial effect of treatment of IMN on risk of death and distant metastasis for patients with medial tumors. They did not show any benefit of IMN irradiation for patients with laterally located tumor [12].

Considering anatomy of the breast and IMN, it is mentioned that there is communication of lymph vessels across the midline and there may be drainage to opposite side especially when some pathways are blocked [13]. Also, unilateral disease becomes bilateral by this route. Hence giving the margin for microscopic disease and taking into account the crossover of lymphatic across midline, do we need to consider bilateral IMN for treatment?

It is clearly mentioned in AJCC staging for breast cancer that contralateral IMN should be considered as metastatic [14]. The survival and prognosis of contralateral IMN as oligo-metastasis is not compared with epsilateral supraclavicular node metastasis or other oligo-metastatic sites in the literature. But making an allowance for an anatomy and relative prognosis of these patients with contralateral IMN metastasis should we classify contralateral IMN in nodal $(\mathrm{N})$ stage like carcinoma lung or metastasis $(\mathrm{M})$ stage of TNM staging?

\section{Conclusion}

Considering the crossover of lymphatic across the midline and balancing the need and toxicity, can we consider the bilateral IMN treatment? A large number of patients need to be studied to verify this hypothesis.

\section{References}

[1] http://globocan.iarc.fr/old/FactSheets/cancers/breast-new.asp.

[2] Gaffney, D.K., Tsodikov, A. and Wiggins, C.L. (2003) Diminished Survival in Patients with Inner versus Outer Quadrant Breast Cancers. Journal of Clinical Oncology, 21, 467-472. http://dx.doi.org/10.1200/JCO.2003.12.047

[3] Veronesi, U., Cascinelli, N., Bufalino, R., Morabito, A., Greco, M. and Galluzzo, D. (1983) Risk of Internal Mammary Node Metastasis and Its Relevance on Prognosis of Breast Cancer Patients. Annals of Surgery, 198, 681-684. http://dx.doi.org/10.1097/00000658-198312000-00002

[4] Heuts, E.M., van der Ent, F.W., von Meyenfeldt, M.F. and Voogd, A.C. (2009) Internal Maary Lymph Drainage and Sentinel Node Biopsy in Breast Cancer-A Study on 1008 Patients. European Journal of Surgical Oncology, 35, 252257. http://dx.doi.org/10.1016/j.ejso.2008.06.1493

[5] Estourgie, S.H., Tnis, P.J., Nieweg, O.E., ValdesOlmos, R.A., Rutgers, E.J. and Kroon, B.B. (2003) Should the Hunt for Internal Mammary Chain Sentinel Nodes Begin? An Evaluation of 150 Breast Cancer Patients. Annals of Surgical Oncology, 10, 935-941. http://dx.doi.org/10.1245/ASO.2003.02.015

[6] van der Ent, F.W., Kengen, R.A., van der Pol, H.A., Povel, J.A., Stroeken, M.D. and Hoofijk, A.G. (2001) Halsted Revisited: Internal Mammary Sentinel Lymph Node Biopsy in Breast Cancer. Annals of Surgery, 234, 79-84. http://dx.doi.org/10.1097/00000658-200107000-00012

[7] Recht, A., Edge, S.B., Solin, L.J., Robinson, D.S., Estabrook, A., Fine, R.E., et al. (2001) Postmastectomy Radiotherapy: Guidelines of the American Society of Clinical Oncology. Journal of Clinical Oncology, 19, 1539-1569.

[8] Noguchi, M., Ohta, N., Thomas, M., et al. (1993) Risk of Internal Mammary Lymph Node Metastasis and Its Prognostic Value in Breast Cancer Patients. Journal of Surgical Oncology, 52, 26-30. 
http://dx.doi.org/10.1002/jso.2930520108

[9] Bouchardy, C., Rapiti, E., Usel, M., Majno, S.B., Vlastos, G., Benhamou, S., Mirabell, R., Neyroud-Caspar, I., Verkooijen, H.M. and Vinh-Hung, V. (2010) Excess of Cardiovascular Mortality among Node Negative Breast Cancer Patients Irradiated for Inner Quadrant Tumors. Annals of Oncology, 21, 459-465. http://dx.doi.org/10.1093/annonc/mdp341

[10] Vrana, D., Gatek, J., Cwiertka, K., Lukesova, L. and Koranda, P. (2013) Internal Mammary Node Irradiation in Breast Cancer. A Review. Biomed Pap Med Fac Univ Palacky Olomouc Czech Repub, 157, 261-265.

[11] Veronesi, U., Marubini, E., Mariani, L., Valagussa, P. and Zucali, R. (1999) The Dissection of Internal Mammary Nodes Does Not Improve the Survival of Breast Cancer Patients. 30 Years Results of a Randomized Trial. European Journal of Cancer, 35, 1320-1325. http://dx.doi.org/10.1016/S0959-8049(99)00133-1

[12] Arriagada, R., Le, M.J., Mouriesse, H., et al. (1988) Long Term Effect of Internal Mammary Chain Treatment. Results of a Multivariate Analysis of 1195 Patients with Operable Breast Cancer and Positive Axillary Nodes. Radiotherapy \& Oncology, 11, 213-222. http://dx.doi.org/10.1016/0167-8140(88)90003-5

[13] Romanes, G.J. (2001) Upper Limb. Pectoral Region and Axilla. In: Cunningham's Manual of Practical Anatomy, Vol. 1, 5th Edition, Oxford Medical Publications, Oxford, 25.

[14] Edge, S.B., Byrd, D.R. and Compton, C.C. (2010) Cancer Staging Handbook. From the AJCC Caner Staging Manual. 7th Edition, Springer Publication, New York, 419-446. 